\title{
Determinants of Compliance for Breast and Cervical Cancers Screening among Female Police Personnel of Mumbai, India-A Cross- Sectional Study
}

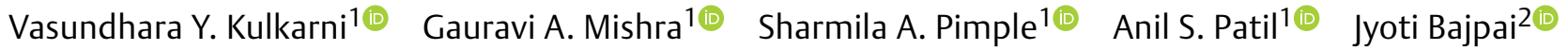 \\ Shylasree $\mathrm{TS}^{3}$ (1) \\ ${ }^{1}$ Department of Preventive Oncology, Centre for Cancer \\ Epidemiology, Tata Memorial Centre, Homi Bhabha National \\ Institute, Mumbai, Maharashtra, India \\ ${ }^{2}$ Department of Medical Oncology, Tata Memorial Centre, Homi \\ Bhabha National Institute, Mumbai, Maharashtra, India \\ ${ }^{3}$ Department of Gynecology Oncology, Tata Memorial Centre, Homi \\ Bhabha National Institute, Mumbai, Maharashtra, India \\ Address for correspondence Gauravi A. Mishra, MD, DPH, DHA, \\ Department of Preventive Oncology, Centre for Cancer Epidemiology, \\ Tata Memorial Centre, Homi Bhabha National Institute, Room No. \\ 314, 3rd Floor, Service Block, E. Borges Marg, Parel, Mumbai 400012, \\ Maharashtra, India \\ (e-mail: gauravi2005@yahoo.co.in; mishraga@tmc.gov.in).
}

Ind J Med Paediatr Oncol 2022;43:60-67.

\section{Abstract \\ Keywords \\ - screening \\ - breast cancer \\ - uterine cervix cancers \\ - police}

Introduction Women working in police force have unique and vital role to play in law enforcement. Although these women have established a secured place for themselves in the police force, they are exposed to several behavioral and health risks apart from job stress. All these can have potentially serious consequences on their well-being. Objectives To determine the compliance to breast and uterine cervical cancers screening and identify predictors of participation in breast and cervical cancers screening among women police personnel.

Materials and Methods This is a cross-sectional study conducted among the Mumbai police personnel during the period 2019 to 2021. All women working for Mumbai police work force in 12 zones were invited to participate in the study. Temporary clinics for screening were set up in different police stations and eligible participants were enrolled after obtaining written informed consent. This was followed by sociodemographic and risk factor assessment, health education program, screening for common cancers conducted by trained primary health workers (breast by clinical breast examination and uterine cervix by visual inspection with $5 \%$ acetic acid). Screen positives were referred according to predefined referral criteria for further investigations and management.

Results A total of 3,017 police women were contacted, among them, 2,629 (87.14\%) were eligible for screening, 2,609 (99.24\%) participated in health education, and 1,839 (69.95\%) complied for breast or cervical cancer screening. Further, compliance for screening of breast and uterine cervix were 1,837 (91.67\%) and 1,297 (64.72\%). A total
DOI https://doi.org/ $10.1055 / \mathrm{s}-0042-1742703$. ISSN 0971-5851. (c) 2022. Indian Society of Medical and Paediatric Oncology. All rights reserved.

This is an open access article published by Thieme under the terms of the Creative Commons Attribution-NonDerivative-NonCommercial-License, permitting copying and reproduction so long as the original work is given appropriate credit. Contents may not be used for commercial purposes, or adapted, remixed, transformed or built upon. (https://creativecommons.org/ licenses/by-nc-nd/4.0/)

Thieme Medical and Scientific Publishers Pvt. Ltd., A-12, 2nd Floor, Sector 2, Noida-201301 UP, India 
of 256 (13.94\%) and 217 (11.81\%) police women were screen positives for breast and cervical cancers. According to multivariate logistic regression analysis, women younger than 50 years, those who were not married or were widowed or separated, postmenopausal women, and those who did not have shift duties had higher compliance for breast and cervix cancers screening.

Conclusion Good participation for breast and cervical cancers screening was seen among the women police personnel. This study has demonstrated that awareness and screening by simple low-cost methods for breast and cervical cancers screening is easily implementable and can be replicated among the women police force in different states of India.

\section{Introduction}

Globally, breast cancer is the leading cancer among women with estimated 2.3 million new cases, representing $11.7 \%$ of all cancer cases worldwide among both sexes combined. According to the 2020 data, it is also the fifth leading cause of cancer mortality considering both genders and topmost cause of cancer deaths among women. Cervical cancer is the fourth most frequently diagnosed cancer and the fourth leading cause of cancer death in women, with an estimated 604,000 new cases and 342,000 deaths worldwide in 2020. Among Indian women, breast cancer represents the highest incidence and mortality followed by cervical cancer. Indian data on incidence and mortality for breast and cervical cancers are 28.8, 18 and 13.3, 11.4, respectively, per 100,000 women. Every year 178,361 and 123,907 new cases of breast and cervical cancers are diagnosed in India. These two cancers account for $31 \%$ of all cancer cases among women in India. ${ }^{1}$ The benefits of screening for breast and cervical cancers are well known (U.S. Preventive Task Force). Screening modalities of breast cancer include clinical breast examination (CBE), self-breast examination, and mammography. ${ }^{2}$ Mammography is not feasible as a population-based breast cancer screening method for India because of resource constraints. One of the largest randomized controlled trials (RCTs) on breast cancer screening by CBE conducted in Mumbai has shown significant downstaging of breast cancer at diagnosis. Results show an overall nonsignificant $15 \%$ reduction in breast cancer mortality, while a subset analysis for women older than 49 years shows a significant reduction of $30 \%$ in breast cancer mortality. This 20 -year study, that evaluated $\mathrm{CBE}$ conducted by trained female health workers in Mumbai, concluded that CBE should be considered for breast cancer screening in low- and middle-income countries (LMICs). ${ }^{3}$ Few other trials of CBE in LMICs have also shown that $\mathrm{CBE}$ can reduce stage at diagnosis of breast cancer. ${ }^{4-6}$ Screening modalities of cervical cancer include Pap cytology, visual inspection with acetic acid (VIA), and human papillomavirus. ${ }^{7}$ Systematic review and meta-analysis conducted by Peirson et al $(2013)^{8}$ highlighted effectiveness of screening for reducing incidence and mortality due to cervical cancers and discussed about optimal timing and frequency of screening. Randomized controlled study conducted by
Shastri et al demonstrated that VIA performed by primary health workers (PHWs) leads to a statistically significant reduction in cervical cancer mortality. ${ }^{9}$ A systematic review on occupational hazards, injuries, and diseases among police officers worldwide has outlined the global impact of occupational hazards, injuries, and diseases in the police force. ${ }^{10}$ Some studies have evaluated breast and cervical cancers screening modalities among female armed forces. ${ }^{11,12}$ According to the World Health Organization, noncommunicable diseases (NCDs) are responsible for $71 \%$ of the global mortality each year. More than $85 \%$ of these deaths occur in LMIC settings. ${ }^{13}$ With this background, the current study was planned to screen Mumbai police personnel for common cancers and NCDs. Here, we present the data of only women police personnel screened for breast and cervical cancers.

\section{Methodology: Materials and Methods}

This is a cross-sectional study, and methodology is shown in -Fig. 1. Mumbai metropolitan region (MMR) police work force is divided into five regions, namely, south, central, east, west, and north. These regions are further divided into 12 zones. Each zone has 5 to 10 police stations. Prior to the proposed study, the permissions were obtained from all respective police authorities belonging to different police stations for implementing the screening camps in different police stations. A pilot study was conducted in one of the police stations to understand the feasibility of screening Mumbai police. The questionnaire for the same was validated in the pilot study. The main study was planned for a duration of 36 months. The primary objective of the current article is to determine the compliance to screening of breast and uterine cervix cancers among women Mumbai police personnel using low cost and effective technologies. The overall objective of the main study is to formulate a demonstrable and sustainable model on prevention, control, and early detection of breast and cervical cancers among the female police personnel in Mumbai. The PHWs received standardized intensive training in the Department of Preventive Oncology Clinic for 3 weeks before they initiated screening police women. All the eligible women participated in breast and cervical cancers screening, and no sample size was calculated. A total of 3,071 police women working in these 


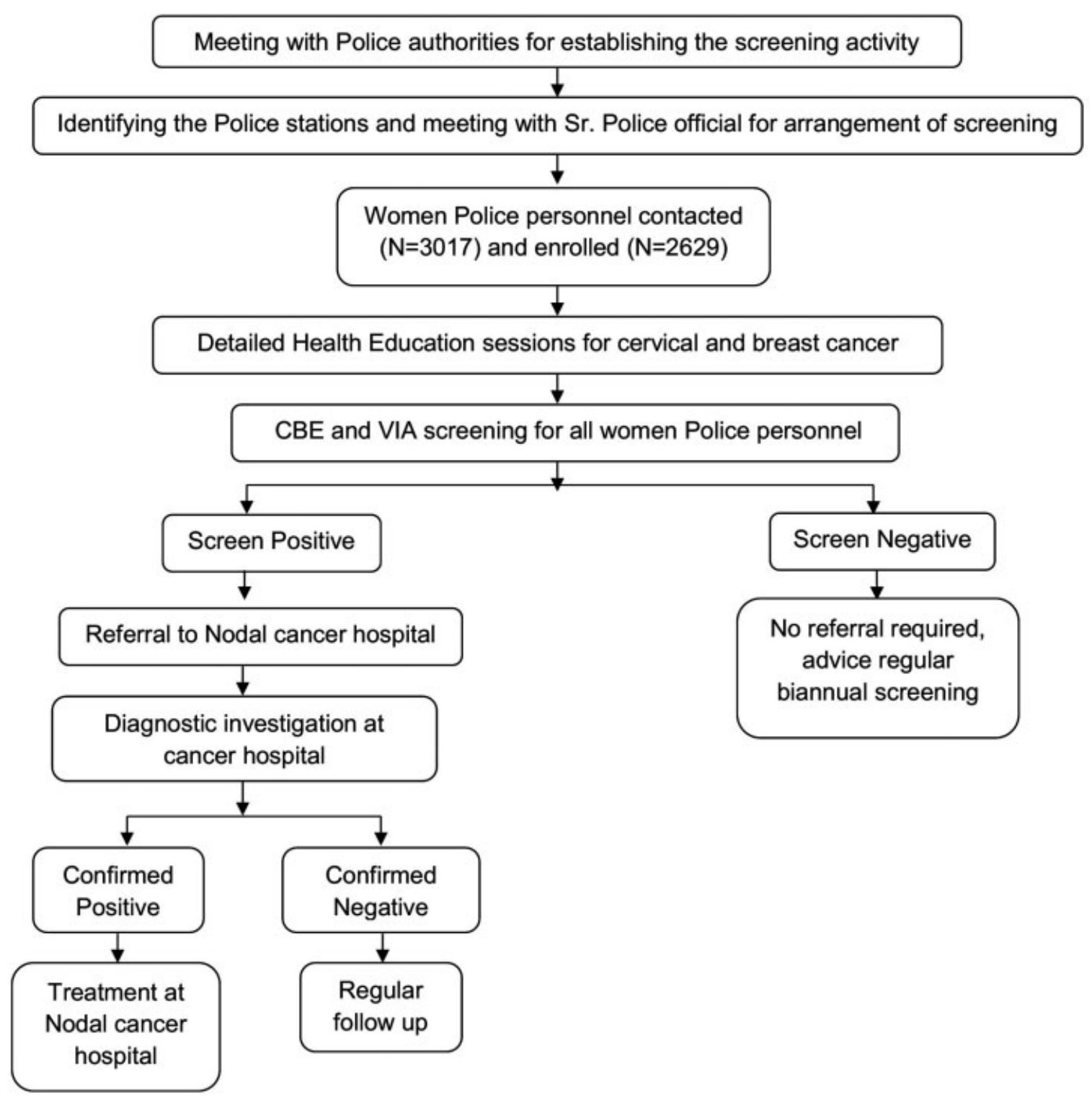

Fig. 1 Study methodology. (CBE) clinical breast examination; (VIA) visual inspection with acetic acid.

police stations were invited for breast and cervical cancers screening. After obtaining informed consent for participating in the study, all the participants were interviewed with a well-structured questionnaire to collect information about their sociodemographic, medical, reproductive, and risk factor history. Detailed health education sessions regarding prevention and early detection for cancers of uterine cervix and breast were conducted for all female police personnel by trained medical social workers. All female police personnel in age group 30 to 65 years were eligible to participate. Any acute or chronic health conditions that may limit the ability of the potential participant to participate in the study were excluded from the study. All female police personnel were offered CBE for breast cancer screening and VIA for cervical cancer screening by trained PHWs. The primary outcome measure was to determine the prevalence of common cancers in this group by conducting screening: breast and uterine cervix for women police personnel. The secondary outcome measure was to formulate a demonstrable and sustainable model on prevention, control, and early detection of breast and cervical cancers among the female police personnel in Mumbai. Compliance in this study refers to adherence to health education or screening. All screenpositive participants were referred to the nodal hospital for further diagnostic investigations and follow-up. Necessary diagnostic confirmatory tests were conducted at the hospital. Predefined referral criteria for breast cancer screening were lump in the breast or under arm, single or multiple duct blood stained nipple discharge, single duct serous nipple discharge, skin changes (peau d'orange appearance/ dimpling of skin), recent changes in the nipple or areola (inversion/retraction), nipple eczema, localized thickening/ asymmetrical nodularity in postmenopausal women, and palpable supraclavicular or axillary lymph nodes. ${ }^{14}$ Referral 
criteria for uterine cervical cancer screening were VIA positive, postmenopausal bleeding, postmenopausal polyp, postcoital bleeding, intermenstrual bleeding, obvious growth on cervix, and excessive foul smelling white discharge per vagina. ${ }^{15}$ All confirmed positive were treated and all confirmed negative cases were advised to follow-up regularly at nodal hospital.

\section{Statistical Analysis}

The data were entered and analyzed using SPSS version 25.0 (IBM SPSS Statistics, Version 25.0, Armonk, New York, United States: IBM Corp.). Qualitative data were expressed in percentages. The determinants of compliance were analyzed by univariate and multivariate logistic regression analyses to evaluate the effects of various sociodemographic and reproductive characteristics of women on compliance, by estimating odds ratios and their $95 \%$ confidence intervals (CIs). A pvalue of $<0.05$ was considered as statistically significant. For the multivariate analysis, significant variables in the univariate analysis were included in multivariate logistic regression model.

\section{Ethics}

The cross-sectional study audit were conducted in accordance with Declaration of Helsinki and Good Clinical Practice as defined by the International Conference on Harmonization. The study was conducted in compliance to the protocol. The cross-sectional study protocol received Tata Memorial Centre Institutional Review Board/Independent Ethics Committee approval prior to initiation of the study dated 26, February 2019. Subject confidentiality was maintained at all times. Ethics committee approval was received, and the trial was registered under ClinicalTrials.gov. CTRI/2019/04/018748.

\section{Results}

A total of 3,017 police personnel from 12 zones under MMR, headquarters, and special branch were eligible for screening. Distribution of sociodemographic and reproductive characteristics among participant women is shown in - Table 1. The mean age of participant police women was $34.92 \pm 7.64$ years and median duration of service in police was 10 (interquartile range $[\mathrm{IQR}]=7$ ) years. Total 2,194 $(83.45 \%)$ were married, 2,251 (85.62\%) were premenopausal women, 239 (9.09\%) were postmenopausal women, and 138 (5.25\%) were perimenopausal women. The mean age at menarche and menopause were $14.53 \pm 1.39$ and $45.51 \pm 4.81$ years, respectively. Mean age at marriage was $24.68 \pm 3.72$, and mean age at first child birth was $26.17 \pm 3.71$. Median number of children was one $(\mathrm{IQR}=1.00)$. Total 1,933 (73.53\%) had history of breastfeeding with $24(\mathrm{IQR}=24)$ months as median duration of breastfeeding, 462 (17.57\%) women had history of gynecological problems, and 122 (4.64\%) had history of breast abnormalities.

A total of 2,568 (97.68\%) were Marathi speaking, 1,860 (70.60\%) were educated to Sr. College and higher, 1,630 (62.00\%) had average monthly income of Rs. 20,001 to
Table 1 Frequency distribution of sociodemographic and reproductive variables

\begin{tabular}{|c|c|}
\hline Variables & $\begin{array}{l}N=2,629 \\
N(\%)\end{array}$ \\
\hline \multicolumn{2}{|l|}{ Age groups (y) } \\
\hline $20-25$ & $66(2.51)$ \\
\hline $26-30$ & $825(31.38)$ \\
\hline $31-35$ & $871(33.13)$ \\
\hline $36-40$ & $314(11.94)$ \\
\hline $41-45$ & $196(7.46)$ \\
\hline $46-50$ & $205(7.80)$ \\
\hline$>50$ & $152(5.78)$ \\
\hline Mean age (y) (SD) & $34.92(7.64)$ \\
\hline \multicolumn{2}{|l|}{ Duration of service in police $(y)$} \\
\hline$<5$ & $239(9.09)$ \\
\hline $6-15$ & $1,746(66.41)$ \\
\hline $16-25$ & $437(16.62)$ \\
\hline$>25$ & $207(7.88)$ \\
\hline Median age in duration of service (IQR) & $10(7.00)$ \\
\hline \multicolumn{2}{|l|}{ Marital status } \\
\hline Married & $2,194(83.45)$ \\
\hline Other & $435(16.55)$ \\
\hline Mean age at marriage $(S D)^{a}$ & $24.68(3.72)$ \\
\hline \multicolumn{2}{|l|}{ Menstrual status ${ }^{a}$} \\
\hline Premenopausal & $2,251(85.62)$ \\
\hline Perimenopausal & $138(5.25)$ \\
\hline Postmenopausal & $239(9.09)$ \\
\hline Mean age at menarche $(S D)^{a}$ & $14.53(1.39)$ \\
\hline Mean age at menopause (SD) ${ }^{\mathrm{a}}$ & $45.51(4.81)$ \\
\hline \multicolumn{2}{|l|}{ Language } \\
\hline Marathi & $2,568(97.68)$ \\
\hline Other & $61(2.32)$ \\
\hline \multicolumn{2}{|l|}{ Education } \\
\hline Illiterate or primary (1-4) & $14(0.53)$ \\
\hline Secondary or higher secondary $(5-12)$ & $759(28.87)$ \\
\hline Sr. college $(13-15)$ & $1,068(40.63)$ \\
\hline Graduates and higher & $788(29.97)$ \\
\hline \multicolumn{2}{|l|}{ Monthly family income in Rs. (per mo) } \\
\hline$<20,000$ & $14(0.53)$ \\
\hline $20,001-50,000$ & $1,630(62.00)$ \\
\hline $50,001-75,000$ & $775(29.48)$ \\
\hline $75,001-100,000$ & $137(5.21)$ \\
\hline$>100,000$ & $73(2.78)$ \\
\hline \multicolumn{2}{|l|}{ Shift duty } \\
\hline Yes & $1,496(56.90)$ \\
\hline No & $1,133(43.10)$ \\
\hline
\end{tabular}


64 Determinants of Compliance of Cervical and Breast Cancers Screening Kulkarni et al.

Table 1 (Continued)

\begin{tabular}{|l|l|}
\hline Variables & $\begin{array}{l}N=2,629 \\
N(\%)\end{array}$ \\
\hline Median number of shift duties (IQR) & $120(40.00)$ \\
\hline Family history of cancer & $268(10.19)$ \\
\hline Yes & $2,361(89.81)$ \\
\hline No & $373(14.19)$ \\
\hline Cancer screening history & $2,256(85.81)$ \\
\hline Yes & $1,933(73.53)$ \\
\hline No & $695(26.44)$ \\
\hline History of breastfeeding ${ }^{\mathrm{a}}$ & $26.17(3.71)$ \\
\hline Yes & $1(1.00)$ \\
\hline No & $462(17.57)$ \\
\hline Mean age at first child birth (SD) & \\
\hline Median number of children (IQR) & \\
\hline Median duration of breastfeeding (IQR) & $24(24)$ \\
\hline Previous history of breast abnormalities & \\
\hline Yes & $122(4.64)$ \\
\hline No & $2,506(95.32)$ \\
\hline Previous history of gynecological problems & \\
\hline Yes & \\
\hline No & \\
\hline
\end{tabular}

Abbreviations: IQR, interquartile range; SD, standard deviation.

aThe total number of women in each variable category differs as a result of missing information about a few participants on the respective variable. History of breastfeeding was computed only among women with live births.

$50,000 /$ month, 1,496 (56.90\%) were working in shifts with median numbers of shifts $120(\mathrm{IQR}=40.00)$ per year, 268 (10.19\%) participants had family history of cancer, and 373 (14.19\%) had undergone cancer screening in the past.

Compliance to screening and health education program (HEP) of the eligible women is represented in -Table 2. Among 3,017 eligible women, 2,629 (87.14\%) were contacted, and 388 refused to participate. Among them, 2,609 (99.24\%) participated in the HEP. The compliance for screening of breast and uterine cervix were 1,837 (91.67\%) and 1,297 (64.72\%). A total of 256 (13.94\%) and 217 (11.81\%) were screen positives for breast and cervical cancers.

Univariate and multivariate logistic regression analyses were carried out to identify predictors of compliance to
Table 3 Multivariate logistic regression analysis identifying predictors of compliance to breast and cervix cancers screening $(N=2,004)$

\begin{tabular}{|c|c|c|c|}
\hline \multirow[t]{2}{*}{ Variables } & \multicolumn{3}{|c|}{ Multivariate analysis } \\
\hline & OR & $95 \% \mathrm{Cl}$ & $p$-Value \\
\hline \multicolumn{4}{|l|}{ Age groups (y) } \\
\hline $30-35$ & 4.829 & $1.067-21.848$ & 0.041 \\
\hline $36-40$ & 5.333 & $1.176-24.181$ & 0.030 \\
\hline $41-45$ & 3.565 & $0.844-15.058$ & 0.084 \\
\hline $46-50$ & 7.231 & $1.916-27.288$ & 0.004 \\
\hline$>50$ & 1 & & \\
\hline \multicolumn{4}{|c|}{ Duration of service in police $(y)$} \\
\hline$<5$ & 0.454 & $0.130-1.594$ & 0.218 \\
\hline $6-15$ & 0.625 & $0.200-1.950$ & 0.418 \\
\hline $16-25$ & 1.630 & $0.558-4.766$ & 0.372 \\
\hline$>25$ & 1 & & \\
\hline \multicolumn{4}{|l|}{ Marital status } \\
\hline Married & 1 & & \\
\hline Other & 1.882 & $1.133-3.125$ & 0.015 \\
\hline \multicolumn{4}{|l|}{ Menstrual status } \\
\hline Premenopausal & 1 & & \\
\hline Perimenopausal & 1.269 & $0.532-3.026$ & 0.591 \\
\hline Postmenopausal & 3.447 & $1.045-11.370$ & 0.042 \\
\hline \multicolumn{4}{|l|}{ Shift duty } \\
\hline Yes & 1 & & \\
\hline No & 1.865 & $1.306-2.663$ & 0.001 \\
\hline \multicolumn{4}{|l|}{ Breastfeed history } \\
\hline No & 1 & & \\
\hline Yes & 1.318 & $0.836-2.076$ & 0.234 \\
\hline
\end{tabular}

Abbreviations: $\mathrm{Cl}$, confidence interval; OR, odds ratio.

breast and cervix cancers screening (-Supplementary Table S1 and -Table 3). According to multivariate logistic regression analysis, predictors viz., age, menstrual status, marital status, and shift duty were found statistically significant. Women younger than 50 years (between 30 and 35 years, 4.829 [1.067-21.848]; between 36 and 40 years, 5.333 [1.176-24.181]; between 41 and 45 years, 3.565 [0.844-15.058]; between 46 and 50 years, 7.231 [1.916-27.288]); not married (1.882 [1.133-3.125]);

Table 2 Compliance to health education and screening

\begin{tabular}{|c|c|c|c|c|c|c|c|}
\hline $\begin{array}{l}\text { Eligible } \\
\text { women }\end{array}$ & $\begin{array}{l}\text { Women contacted } \\
\text { (\% of eligible) }\end{array}$ & $\begin{array}{l}\text { Participation } \\
\text { in health } \\
\text { education } \\
\text { (\% of eligible) }\end{array}$ & Site & $\begin{array}{l}\text { Eligible } \\
\text { women }\end{array}$ & $\begin{array}{l}\text { Compliance to } \\
\text { screening (\%) }\end{array}$ & $\begin{array}{l}\text { Screening }+ \text { ve } \\
\text { (\% of screened) }\end{array}$ & $\begin{array}{l}\text { Screening }+ \text { ve (\% } \\
\text { of contacted) }\end{array}$ \\
\hline \multirow[t]{2}{*}{3,017} & \multirow[t]{2}{*}{$2,629(87.14)$} & \multirow[t]{2}{*}{$2,609(99.24)$} & Breast & \multirow{2}{*}{$\begin{array}{l}2,004 \\
(76.23)\end{array}$} & $1,837(91.67)$ & $256(13.94)$ & $256(9.74)$ \\
\hline & & & Cervix & & $1,297(64.72)$ & $217(11.81)$ & $217(8.25)$ \\
\hline
\end{tabular}


postmenopausal women (3.447 [1.045-11.370]); and who were not working in shift (1.865 [1.306-2.663]) had higher compliance to breast and cervix cancers screening.

\section{Discussion}

Distribution of sociodemographic and reproductive characteristics among participant women is shown in - Table 1 . The mean age of participant police women was $34.92 \pm 7.64$ years. The mean age of women participating in study at armed forces in Canada was 38.6 years. ${ }^{12}$ A communitybased randomized controlled study has reported mean age of participation in study and control arm as $44.84 \pm 7.86$ and $44.92 \pm 8.01$ years which is comparatively higher than our study. Younger mean age of participation could be attributed to early recruitment of women in police force. ${ }^{9}$ In our study, the median duration of service in police was $10(\mathrm{IQR}=7)$ years. In cross-sectional study conducted by Braun et al among navy women for cervical cancer screening, the range for years of service for ship-based participants was 1 to 24 years and mean years of service was $7.2 \pm 7.32$ years, compared with their shore-based cohort (range: 1-9.5), mean years of service was $4.1 \pm 2.9$ years. ${ }^{16}$ In our study, most of police women $(83.45 \%)$ were married, while in a study conducted among air force women by Frommelt et al, ${ }^{17}$ only $60 \%$ of the women were married. This difference may be because most police women in current study belonged to nearby district places of Maharashtra, and with strong cultural family background had likely got married at an earlier age. The mean age at menarche and menopause was $14.53 \pm 1.39$ and $45.51 \pm 4.81$ years, respectively, which is far more similar to the study conducted by Dinshaw et al ${ }^{18}$ wherein the mean age of menarche was around 13.8 years, and the mean age of menopause was around 43.5 years. The mean age of marriage in our study was $24.68 \pm 3.72$ years, while the mean age of marriage in a community-based trial was 18 years. The mean age of first child birth in our study was $26.17 \pm 3.71$ years, while the mean age of first child birth from the findings of a community-based randomized trial was 21 years. $^{18}$ In our study, history of breastfeeding their kids was present in $73.53 \%$ participants, while history of breastfeeding in a RCT in Mumbai was $98 \%{ }^{18}$ This may be because the police women had to get back to duties after their maternity leave. In our study, history of previous consultation for breast or gynecological complaints did not affect participation for screening, while in a communitybased trial conducted by Dinshaw et al, ${ }^{18}$ this was a significant predictor for compliance to breast and cervical cancers screening. Most of the police women were native Marathispeaking women and educated up to Sr. college and higher with average monthly income between Rs. 20,000 and 50,000 . In a study conducted by Allen et al promoting breast and cervical cancers screening at workplace, participants were predominantly white, well educated, employed in professional occupations, and had annual household incomes of $\$ 50,000$ or more. ${ }^{19}$ Median number of shift duties were 120 shifts per year in our study. Women who were working in shifts complied less with breast and cervical cancers screening. In a study conducted by Braun et al on U.S. navy women's experiences with abnormal cervical screenings, it was noted that change of duty stations, military deployments, and assignments in remote locations could prevent the timely notification of abnormal results and affect the follow-up. ${ }^{16}$ In the present study, $10.19 \%$ participants had a family history of cancer, and $14.19 \%$ had undergone cancer screening in the past. In a trial conducted by Amin et $\mathrm{al}^{20}$ irrespective of cost and travel barriers, one time screening participation was high, but was lower with regard to women who have had undergone recent mammogram. In one of the community-based study conducted in Mumbai, neither family history of cancer nor history of cancer screening was found to be significant predictors of participation in breast cancer screening. ${ }^{21}$ In the present study, compliance to screening for breast and uterine cervix cancers was 91.67 and $64.72 \%$, respectively. These compliance rates were determined when police women were screened in their respective police stations. The compliance rates for screening were higher in community-based screening studies. ${ }^{18,21}$ In the present study, univariate and multivariate logistic regression analyses were carried out to identify predictors of compliance to breast and cervix cancers screening. Women younger than 50 years, not married, postmenopausal women, and women who were not working in shift duties had higher compliance to breast and cervix cancers screening. Inferences from the district-level analysis conducted to assess predictors of uptake of screening and geospatial variation of cervical and breast cancers screening across 640 districts were women belonging to general caste, residing in rural areas, currently married, and well-off economically complied for both cervical and breast cancers screening. Additionally, having health insurance was positively associated with the uptake of cervical cancer screening only. This shows that there is lot of geographical variation with respect to breast and cervical cancers screening among the districts of India. ${ }^{22}$ In a study conducted by Lairson et al among the veterans, education, income, insurance, and perceived risk of breast cancers were associated with better compliance to mammographic screening. However, age, smoking, and waiting period were inversely associated with compliance to mammographic screening. ${ }^{23} \mathrm{~A}$ total of 13.94 and $11.81 \%$ were screened positive for breast and cervical cancers. Findings of retrospective review of the laboratory information system at Walter Reed Army Medical Center show that among the 21 years old, $22.5 \%$ (95\% CI: 17.9-27.8\%) had highgrade squamous intraepithelial lesion or more severe lesions on their first or second Pap and 23.2\% (95\% CI: 18.6-28.5\%) had high-grade squamous intraepithelial lesion or more severe lesions on a subsequent biopsy. ${ }^{24}$

A review article by Braun et al concludes that cervical cancer risk factors are higher among active duty service women. To maintain the military readiness, evidence-based prevention efforts are required to address the challenges in the existing health care system that might increase the likelihood of getting cervical cancer. ${ }^{25}$ Women working in armed forces, navy, or police force need attention even after they are deployed in their respective services; $21 \%$ of soldiers 
(52 of 251 soldiers) had gynecologic problems during deployment; however, $44 \%$ ( 23 of 52 soldiers) were unable to receive the medical care they needed to resolve this issue. $^{26}$ To prevent this increasing morbidity and mortality, women working for police force need effective awareness and screening programs for breast and cervical cancers. Limitation of this study was that around 388 female participants did not participate. This could be due to their odd duty hours and transfers to different police stations during the screening program.

\section{Conclusion}

Awareness and screening for breast and uterine cervical cancers play an important role in early diagnosis. Successful implementation of this study demonstrates that this study can be replicated among the police women working in different states of India. Nonetheless, to increase the screening uptake, efforts are required to systematically promote these simple screening methods apart from their regular medical health checkup.

\section{Note}

This work is attributed to the Department of Preventive Oncology, Centre for Cancer Epidemiology, Tata Memorial Hospital, Homi Bhabha National Institute, E. Borges Marg, Parel, Mumbai 400012, Maharashtra, India.

\section{Funding}

This study is supported by Tata Trusts and Tata Memorial Hospital.

\section{Presentations at a Meeting}

This work has been presented at the OCCUCON 2019 conference held at Rajkot, Gujarat in January 2019 and the OCCUCON 2020 conference held at Mumbai during January 2020, and the abstracts were published as Abstracts 29 \& 50: OCCUCON Abstracts. Indian J Occup Environ Med 2020;24(Suppl S1):21-41. It has also been presented in the Public Health Conference 2021.

\section{Conflict of Interest \\ None declared.}

\section{Acknowledgements}

The authors wish to acknowledge the contributions of the following persons who have been directly or indirectly associated with the program, viz., Dolorossa Fernandes, Parishi Majmudar, Sushma Gaikwad, Anjali Salvi, Anuradha Patil, Meena Kule, Sangeeta Chavan, Neelam Hardikar, Mrudula Meher, Pratiksha Dongre, Tushar Jadhav, Pramod Kharade, Vandita Pahwa, Amey Oak, Chandrika Dandekar, Subita Patil, Rajat Bhardwaj, Alay Parikh, S.M. Patil, C.S. Pramesh, Rajendra A. Badwe, and all staff of the Department of Preventive Oncology at Tata Memorial Hospital and of the Police Department for supporting the project. The authors specially acknowledge the sup- port of Ambika N., DCP, Mumbai Police and Jt. Commissioner of Police (Admin) for their whole-hearted support for the study.

\section{References}

1 Sung H, Ferlay J, Siegel RL, et al. Global cancer statistics 2020: GLOBOCAN estimates of incidence and mortality worldwide for 36 cancers in 185 countries. CA Cancer J Clin 2021;71(03):209-249

2 US Preventive Task Force recommendation. Accessed September 5, 2021 at: https://www.uspreventiveservicestaskforce.org/ uspstf/recommendation/breast-cancer-screening

3 Mittra I, Mishra GA, Dikshit RP, et al. Effect of screening by clinical breast examination on breast cancer incidence and mortality after 20 years: prospective, cluster randomised controlled trial in Mumbai. BMJ 2021;372:n256

4 Sankaranarayanan R. Screening for cancer in low- and middleincome countries. Ann Glob Health 2014;80(05):412-417

5 Devi BC, Tang TS, Corbex M. Reducing by half the percentage of late-stage presentation for breast and cervix cancer over 4 years: a pilot study of clinical downstaging in Sarawak, Malaysia. Ann Oncol 2007;18(07):1172-1176

6 Sankaranarayanan R, Ramadas K, Thara S, et al. Clinical breast examination: preliminary results from a cluster randomized controlled trial in India. J Natl Cancer Inst 2011;103(19): 1476-1480

7 US Preventive Task Force recommendation. Accessed September 5, 2021 at: https://www.uspreventiveservicestaskforce.org/ uspstf/recommendation/cervical-cancer-screenings

8 Peirson L, Fitzpatrick-Lewis D, Ciliska D, Warren R. Screening for cervical cancer: a systematic review and meta-analysis. Syst Rev 2013;2(01):35

9 Shastri SS, Mittra I, Mishra GA, et al. Effect of VIA screening by primary health workers: randomized controlled study in Mumbai, India. J Natl Cancer Inst 2014;106(03):dju009

10 Mona GG, Chimbari MJ, Hongoro C. A systematic review on occupational hazards, injuries and diseases among police officers worldwide: policy implications for the South African Police Service. J Occup Med Toxicol 2019;14(01):2

11 Merdiemah GE. Breast Cancer Screening among Female Personnel of the Ghana Armed Forces, Accra (PHD dissertation, University of Ghana).

12 Naicker K, Hawes R. Cervical cancer screening in the Canadian armed forces: an estimation of screening participation rates using the CF-HERO surveillance system. Cancer Epidemiol 2020; 65:101670

13 WHO factsheet on NCDs [Internet]. [Cited September 18, 2018]. Accessed August 6, 2021 at: http://www.who.int/news-room/ fact-sheets/detail/noncommunicable-diseases

14 Basset AA. Physical examination of the breast and breast selfexamination. In: Miller AB, ed. Screening for Cancer. Orlando: Academic Press; 1985

15 Sankaranarayan R, Wesley R. A Practical Manual on Visual Screening for Cervical Neoplasia. IARC Technical Publication No. 41. Lyon: IARC Press; 2003

16 Braun LA, Kennedy HP, Sadler LS, Dixon J, Womack J, Wilson C. US Navy women's experience of an abnormal cervical cancer screening. J Midwifery Womens Health 2016;61(02):249-256

17 Frommelt RA, Peterson MR, O'Leary TJ. A comparison of cervical pathology between United States Air Force women who did and did not serve in the Persian Gulf War. Ann Epidemiol 2000;10(05): 285-292

18 Dinshaw K, Mishra G, Shastri S, et al. Determinants of compliance in a cluster randomised controlled trial on screening of breast and cervix cancer in Mumbai, India. Oncology 2007;73 (3-4):145-153 
19 Allen JD, Stoddard AM, Mays J, Sorensen G. Promoting breast and cervical cancer screening at the workplace: results from the Woman to Woman Study. Am J Public Health 2001;91(04): 584-590

20 Amin A, Shriver CD, Henry LR, Lenington S, Peoples GE, Stojadinovic A. Breast cancer screening compliance among young women in a free access healthcare system. J Surg Oncol 2008;97(01): 20-24

21 Kulkarni SV, Mishra GA, Dusane RR. Determinants of compliance to breast cancer screening and referral in low socio-economic regions of urban India. Int J Prev Med 2019;10:84

22 Shui Y, Xu D, Liu Y, Liu S. Work-family balance and the subjective well-being of rural women in Sichuan, China. BMC women's health 2020;20(01):1
23 Lairson DR, Chan W, Newmark GR. Determinants of the demand for breast cancer screening among women veterans in the United States. Soc Sci Med 2005;61(07):1608-1617

24 Natale K, Howard RS, Crothers BA. To Screen or Not to Screen: Presence of High-Grade Squamous Intraepithelial Lesions or Worse in a Regional Military/Beneficiary Population Under 21 Years of Age. J Am Soc Cytopathol 2013;1(02):S39-40

25 Braun LA, Kostas-Polston EA, Miedema J, Hoffecker L, Wilson C. A scoping review of cervical cancer risk factors, prevention, diagnosis, and treatment in U.S. Active Duty Military Women. Womens Health Issues 2021;31(Suppl 1):S53-S65

26 Thomson BA, Nielsen PE. Women's health care in Operation Iraqi Freedom: a survey of camps with echelon I or II facilities. Mil Med $2006 ; 171(03): 216-219$ 